\title{
QUIXOTADA LINGUÍSTICA \\ PARA ALÉM DA BRAVURA E DAS ESTABILIDADES, INVENÇÕES DOS QUE NÃO PODEM CORRER
}

\author{
Miguel Angel Schmitt Rodriguez \\ UFSC / CNPq
}

Dom Quixote constituiu-se como um clássico da literatura ocidental através das interpretaçôes canônicas que enfatizaram as qualidades pedagógicas que as aventuras do herói cervantino possibilitam ao leitor. No presente artigo, entretanto, busca-se pensar tal texto para além dos ensinamentos humanistas que a tradicão procurou destacar. Insinua-se, por exemplo, que a morte de Deus anunciada por Nietzsche poderia guardar relaçôes íntimas com os disparates quixotescos. Busca-se, ademais, enfatizar a presença de uma escritura que destaca a instabilidade dos significantes e que apontaria para uma prática de operação soberana ou de experiência interior tal qual sugerida por Georges Bataille.

Palavras-ChaVE: Dom Quixote. Morte de Deus. Operação soberana.
Don Quijote was established as a classic of Western literature through the canonical interpretations that emphasized the pedagogical qualities that the adventures of the Cervantine's hero allow the reader. In this article, however, we try to think this text beyond the teachings that humanist tradition sought to highlight. It insinuates, for example, that the death of God proclaimed by Nietzsche could keep close relationships with the quixotic nonsense. It seeks, moreover, to emphasize the presence of a scripture that highlights the significant instability that would point towards a practice of sovereign operation or inner experience as it was suggested by Georges Bataille.

KEWWorDS: Don Quijote. Death of God. Sovereign operation.

Miguel Angel Schmitt Rodriguez é doutorando em Literatura na Universidade Federal de Santa Catarina e pesquisador do Núcleo Juan Carlos Onetti de Estudos Literários Latino-americanos. 


\title{
QUIXOTADA LINGUÍSTICA \\ PARA ALÉM DA BRAVURA E DAS ESTABILIDADES, INVENÇÕES DOS QUE NÃO PODEM CORRER
}

\author{
Miguel Angel Schmitt Rodriguez
}

Both in and out of the game and watching and wondering at it.

Walt Whitman, Song of myself

Nos últimos capítulos da primeira parte do Ingenioso hidalgo cervantino, podemos ler no diálogo do cônego e do cura, durante o retorno de Dom Quixote à sua aldeia, uma explicitação, não de toda estranha, sobre certa compreensão do que seja a literatura, ou do que ela deveria ser. Dom Quixote se deixa ser transportado enjaulado, acreditando sofrer de encantamento, quando o cura, a parte, explica ao cônego "el principio y causa de su desvarío" ${ }^{1}$. Ao perceber a importância que a leitura dos livros de cavalaria recebia nesse processo de perda da razão que acometeu o fidalgo, o cônego condena, num longo discurso, o estágio em que se encontrava a produção literária:

\footnotetext{
Verdaderamente, señor cura, yo hallo por mi cuenta que son perjudiciales en la república estos que llaman libros de caballerías [...] según a mí me parece, este género de escritura y composición cae debajo de aquel de las fábulas que llaman milesias, que son cuentos disparatados, que atienden solamente a deleitar... ${ }^{2}$
}

Menéndez Pelayo, em discurso realizado na Universidad Central de Madrid em motivo do terceiro centenário do Quijote, pôde fazer ecoar a condenação do cônego, atualizando-a no começo do século XX. Refletindo sobre o ocaso dos "romances de cavalaria" naquele contexto, apontava o crítico espanhol:

Pues ia quién no maravilla que en la época más clásica de España, en el siglo espléndido del Renacimiento, que con razón llamamos de oro [...] fuese entrete-

\footnotetext{
${ }^{1}$ SAAVEDRA, Miguel de Cervantes. El ingenioso hidalgo Don Quijote de La Mancha. Madrid: M. Aguilar, 1947, p. 666.

2 ibidem, p. 666.
} 
nimiento común de grandes y pequeños, de doctos e indoctos, la lección de unos libros que, exceptuados cuatro o cinco que merecen alto elogio, son tales como los describió Cervantes: "En el estilo duros, en las hazañas increíbles, en los amores lascivos, en las cortesías mal mirados, largos en las batallas, necios en las razones, disparatados en los viajes $y$, finalmente, dignos de ser desterrados de la república cristiana como gente inútil?" ${ }^{3}$

A passagem cervantina referida faz parte do mesmo discurso que citamos anteriormente; ela é expressão e opinião de uma personagem do livro. Do modo como o então diretor da Biblioteca Nacional da Espanha se refere, entretanto, parece ser a opinião de Cervantes.

Ao escutar o eco das palavras do cônego - que condena os romances de cavalaria e com isto a loucura de Quixote - na voz de Menéndez Pelayo não podemos se não perceber a cumplicidade entre a maneira em que a tradição da cristandade e a tradição acadêmica, bacharelesca, costumaram avaliar e compreender a literatura, bem como a arte de maneira geral.

Para o cônego, personagem de Cervantes, os ditos romances de cavalaria só se tornariam belos se procurassem construir um corpo homogêneo que por meio do exemplo buscassem educar o leitor. Por essa via, poderiam compor "una tela de varios y hermosos lizos tejida [...] que consiga el fin mejor que se pretende en los escritos, que es enseñar y deleitar juntamente" ${ }^{4}$. Ora, precisamente é essa qualidade educativa que Menéndez Pelayo procura atribuir ao livro de Cervantes, ignorando o tom disparatado da aventura quixotesca. Segundo o entusiasta da efeméride, a celebração do Quijote deveria ser pensada na perspectiva dos "cánones estéticos", a qual conduz "los espíritus a la esfera de lo ideal; la ley superior, que resuelve las particulares antinomias" ${ }^{5}$. 0 horizonte, nessa perspectiva, é o da necessidade de se estabelecer cânones: regras gerais para que se possam inferir regras especiais; necessidade do uso da régua para que se possa medir e avaliar os casos particulares. Fácil é perceber de que se está operando, dessa forma, num âmbito próprio ao da tradição metafísica.

Nada espanta, portanto, a opinião de que a loucura de Dom Quixote "es una mera alucinación respecto del mundo exterior, una falsa combinación e

\footnotetext{
${ }^{3}$ PELAYO, Marcelino Menéndez. Cultura y literatura de Miguel de Cervantes y elaboración del Quijote. In: San Isidoro, Cervantes y otros estudios. Buenos Aires: Espasa-Calpe, 1947, p. 102-103.

4 SAAVEDRA, Miguel de Cervantes. El ingenioso hidalgo Don Quijote..., op. cit., p. 669.

5 PELAYO, Marcelino Menéndez. Cultura y literatura de Miguel de Cervantes..., op. cit., p. 76.
} 
interpretación de datos verdaderos" lada" do cavaleiro "continúan resplandeciendo con inextinguible fulgor las puras inmóviles y bienaventuradas ideas de que hablaba Platón"7 . Também, não deveria nos espantar o fato de a expressão "cônego", bem como "canónigo" no original, derivar, justamente, da expressão grega kanon, que é de onde se origina, igualmente, a palavra "cânone" ${ }^{8}$.

Percebe-se que o processo de canonização do Quijote insere-se numa ótica que demanda a constituição da ideia do artista como gênio, da noção de obra imortal e constituída por valores universais. E, se Miguel de Unamuno, na obra Vida de Don Quijote y Sancho, publicada no mesmo ano de 1905 - mas, segundo o autor, não em motivo da comemoração - quis "intentar la santa cruzada de ir a rescatar el sepulcro del Caballero de la Locura del poder de los hidalgos de la Razón" ${ }^{\prime}$, nem por isso deixou de operar por meio desses "universais". Em ensaio posterior, intitulado El caballero de la triste figura, Unamuno, ainda que sob um olhar distinto ao de Menéndez Pelayo, não abandonava o horizonte das verdades últimas e dava-lhe novo alento ao afirmar, por exemplo, que "La fuerza de la verdad de Don Quijote está en su alma, en su alma castellana y humana, y la verdad de su figura en que refleje esta tal alma" ${ }^{10}$.

Não é difícil notar que estamos, todavia, saturados de discursos que requerem o estabelecimento e identificação de verdades. Em 2004, Mario Vargas Llosa, no prefácio à edição comemorativa do quarto centenário, ainda insiste em homogeneizar as diferenças: por meio da velha dialética procura ver em Dom Quixote e Sancho "una sola sombra' [...] que retrata en toda su contradictoria y fascinante verdad la condición humana" ${ }^{11}$. Desde essa matriz logo

\footnotetext{
6 ibidem, p. 109.

7 ibidem, p. 109.

${ }^{8}$ CUNHA, Antônio Geraldo da. Dicionário etimológico da língua portuguesa. Rio de Janeiro: Lexicon, 2010, p. 122.

9 UNAMUNO, Miguel de. El sepulcro de Don Quijote. In: Vida de Don Quijote y Sancho. Madrid: Espasa-Calpe, 1985, p. 13.

${ }^{10}$ idem, El Caballero de la triste figura. Ensayo iconológico. In: El caballero de la triste figura. Madrid: Espasa-Calpe, 1980, p. 72.

${ }^{11}$ LLOSA, Mario Vargas. Una novela para el siglo XXI. In: CERVANTES, Miguel. Don Quijote de La Mancha. Edición del IV Centenario. São Paulo: Real Academia Española / Asociación de Academias de la Lengua Española, 2004, p. XXVIII.
} 
se compreende a reiteração da imagem de Dom Quixote como aquela do cavaleiro andante que "motivado por una vocación generosa, se lanza por los caminos, a buscar remedio para todo lo que anda mal en el planeta"12.

Vladimir Nabokov, curiosamente em um curso de Humanidades do programa de Educação Geral da universidade de Harvard, pôde, já no início da década de 50, assinalar que "tomar este libro amargo y bárbaro como muestra de lo humano y lo humorístico es una actitud y un juicio que no tiene fundamento" 13 . Chamando a atenção para as cenas violentas da narrativa, asseverava: "Las dos partes del Quijote componen una auténtica enciclopedia de la crueldad" ${ }^{14}$. Também Nietzsche, no segundo tratado de La genealogía de la moral, havia destacado: "en la actualidad leemos todo el Quijote con un regusto amargo en la boca, sintiéndonos casi torturados". No entanto, ponderava: "con lo que les resultaríamos muy extraños e incomprensibles a su autor y a su época: ellos lo leían, con la mejor de las conciencias, como el más divertido de los libros" ${ }^{15}$. Portanto, apesar de ambas as observações atentarem para o tom despiedoso, logo se vê a distância das críticas: enquanto Nabokov ironiza as leituras humanistas do Quijote parecendo censurar Cervantes através da denúncia das crueldades, Nietzsche procura atacar a moral do humanismo e não demonstra pudor ao afirmar: "Sin crueldad no hay fiesta: así lo enseña la más vieja y larga historia del hombre" ${ }^{16}$.

Parece não ser de todo desnecessário retornar a pensar a arte longe das prédicas de salvação próprias dos discursos da ciência e/ou religiões, bem como, longe das costumeiras avaliações pautadas por sentimentos morais. No capítulo 48 da primeira parte, Dom Quixote responde aos insistentes avisos de Sancho sobre a "real" identidade dos "falsos" encantadores com o seguinte argumento:

es fácil a los encantadores tomar la figura que se les antoja y habrán tomado las destos nuestros amigos [o cura e o barbeiro] para darte a ti ocasión de que pienses lo que piensas y ponerte en un laberinto de imaginaciones que no aciertes a salir del aunque tuvieses la soga de Teseo. ${ }^{17}$

\footnotetext{
${ }^{12}$ ibidem, p. XX.

${ }^{13}$ NABOKOV, Vladimir. El Quijote. Trad. Marisa Balseiro. Barcelona: Ediciones B, 1987, p. 110.

${ }^{14}$ ibidem, p. 76-77.

${ }^{15}$ NIETZSCHE, Friedrich. La genealogía de la moral. Un escrito polémico. In: Friedrich Nietzsche II. Trad. José Mardomingo Sierra. Madrid: Gredos, 2009, p. 630.

${ }^{16}$ ibidem, p. 630.

${ }^{17}$ SAAVEDRA, Miguel de Cervantes. El ingenioso hidalgo Don Quijote..., op. cit., p. 679.
} 
Desde esse enunciado, creio que se poderia extrair a seguinte asserção: a literatura é encantamento e é convite a um labirinto de imaginações. Por que não deveríamos sentir e ouvir com essa empatia os discursos quixotescos? Por que não rechaçar, de uma vez, as torpes recomendações do cônego que insiste em buscar na literatura leituras "que redunde en aprovechamiento de su conciencia y en aumento de su honra" ${ }^{18}$ ?

Michel Foucault, em As palavras e as coisas, considerou o Quixote como "a primeira das obras modernas". E, o que é mais importante, viu na narrativa de Cervantes o momento onde "a linguagem rompe seu velho parentesco com as coisas" ${ }^{19}$; momento onde as palavras deixam de ser representantes de realidades exteriores e postulam elas mesmas o universo da imaginação, que é a própria realidade da narrativa. $\mathrm{O}$ âmbito próprio a esses procedimentos Foucault designou de "soberania solitária".

Se retomarmos o conceito de soberania que Carl Schmitt expôs em 1922 no livro Teologia Política vamos ter que "Soberano é aquele que decide sobre o Estado de exceção" e que, dessa forma, "é competente para decidir sobre a suspensão total da Constituição" ${ }^{20}$. Tal conceito, se pensado além dos limites da sociologia política ou jurídica, pode estabelecer certa correspondência com a noção de Georges Bataille acerca da "experiência interior". Segundo expôs o autor no livro homônimo publicado em 1943: "La experiencia interior responde a la necesidad en la que me encuentro - y conmigo, la existencia humana - de ponerlo todo en tela de juicio (en cuestión) sin reposo admisible ${ }^{21}$. Ora, colocar tudo em questão é precisamente suspender a legitimidade das premissas que outorgam certa legalidade para uma dada circunstância.

No prólogo do Quijote, Cervantes nos traz a imagem do escritor que vive a indecisão para determinar o caminho e a forma de apresentar o livro, e com isto já o apresenta, fazendo do prolongamento o seu prólogo:

\footnotetext{
18 ibidem, p. 685.

${ }^{19}$ FOUCAULT, Michel. As palavras e as coisas. Uma arqueologia das ciências humanas. Trad. Salma T. Muchail. São Paulo: Martins Fontes, 2007, p. 67.

${ }^{20}$ SCHMITT, Carl. Teologia política. In: A crise da democracia parlamentar. Trad. Inês Lohbauer. São Paulo: Scritta, 1996, p. 87-88.

${ }^{21}$ BATAILLE, Georges. La experiencia interior. Seguida de Método de meditación y de postscriptum 1953. Trad. Fernando Savater. Madrid: Taurus, 1986, p. 13.
} 
Muchas veces tomé la pluma para escribilla, y muchas la dejé, por no saber lo que escribiría; y estando una suspenso, con el papel delante, la pluma en la oreja, el codo en el bufete y la mano en la mejilla, pensando lo que diría, entró a deshora un amigo mío... ${ }^{22}$

Mais adiante, ao explicar, ao amigo, a causa de sua indeterminação, que era sobretudo um rechaço aos protocolos e formalidades vãs que então imperavam nas práticas editoriais, confessa:

En fin, señor y amigo mio [...], yo determino que el señor Don Quijote se quede sepultado en sus archivos de la Mancha hasta que el Cielo depare quien le adorne de tantas cosas como le faltan; porque yo me hallo incapaz de remediarlas, por mi insuficiencia y pocas letras, y porque, naturalmente, soy poltrón y perezoso de andarme buscando autores que digan lo que yo me sé decir sin ellos. De aquí nace la suspensión y elevamiento amigo, en que me hallastes; bastante causa para ponerme en ella la que de mí habéis oído. ${ }^{23}$

Tudo se resolve quando o narrador do prólogo ouve o conselho de seu amigo, que não é outro a não ser retomar os procedimentos costumeiros com a inscrição de sonetos, epigramas e elogios, além das citações de clássicos latinos e da sagrada escritura. Ou seja, aquilo que justamente se questionava é, inusitadamente, proposto como meio de solucionar o caso. O narrador aceita as recomendações.

Agora, veja que, narrando toda essa situação, a recomendação não é aceita de fato, mas tão somente como forma de ironia da real situação. Torna-se muito revelador essa confissão que acaba por levar à escrita, ou melhor, ao procedimento da escritura um estatuto inestimável para a possibilidade de realização daquilo que Bataille chamou de "operação soberana". Esse estado de suspensão do qual nos fala o narrador nos remete aos procedimentos próprios da "experiência interior" que aludíamos anteriormente:

Si vivimos sin repulsa bajo la ley del lenguaje, estos estados están en nosotros como si no existiesen. Pero si chocamos contra tal ley, podemos, de pasada, detener la conciencia sobre uno de ellos $y$, haciendo callar en nosotros el discurso, detenernos en la sorpresa que nos proporciona. Más vale en ese caso encerrarse, apagar las luces, permanecer en ese silencio suspendido... ${ }^{24}$

\footnotetext{
${ }^{22}$ SAAVEDRA, Miguel de Cervantes. El ingenioso hidalgo Don Quijote..., op. cit., p. 09-10. Grifo nosso.

${ }^{23}$ ibidem, p. 11. Grifo nosso.

${ }^{24}$ BATAILLE, Georges. La experiência interior, op. cit., p. 24.
} 
Observe-se que a ironia traz junto consigo o paradoxo que põe o narrador dentro e fora da situação narrada. Como pontua Foucault "O texto de Cervantes se dobra sobre si mesmo, se enterra na sua própria espessura e torna-se para si objeto de sua própria narrativa" ${ }^{25}$. Podemos pensar que, em certa medida, a escritura do livro de Cervantes, estaria, sob essa perspectiva, operando dentro daquilo que Agamben chamou de "paradoxo do êxtase bataillano", ou seja, "que o sujeito deve estar lá onde não pode estar" ${ }^{26}$. E, conforme o mesmo Agamben observou, tal paradoxo mantém uma correspondência com o paradoxo que Schmitt apontava em relação à soberania e que dizia respeito ao fato de que "o soberano está, ao mesmo tempo, fora e dentro do ordenamento" $^{27}$.

Vale destacar que "operação soberana" e "estados de êxtases" são expressões bataillanas que se vinculam diretamente ao tema da "experiência interior". Sobre o desenvolvimento de tais condições, Bataille ressaltava: "Si no supiésemos dramatizar, no sabríamos salir de nosotros mismos"; e mais adiante: "Si no hubiésemos sabido dramatizar, no sabríamos reír" 28.

Nietzsche, em um fragmento póstumo datado do verão de 1875 teria anotado: "Uno de los libros más nocivos es Don Quijote" ${ }^{29}$. E logo, em outra ocasião, no verão de 1877 , destacava "es un hecho que con ningún libro se ha reído tanto como con el Don Quijote" ${ }^{30}$. Nesse intervalo, em dezembro de 1875, recomendava ao seu então amigo Erwin Rohde, com a seguinte tonalidade, a releitura da obra:

Pero quizá podrías volver a leer ahora Don Quijote - no porque sea la lectura más alegre, sino porque es la más áspera que conozco, la acometí en las vacaciones de verano [quando anotou ser "Uno de los libros más nocivos"], y todo padecimiento personal pareció empequeñecer hasta el punto de ser digno de que uno se riera de ello abiertamente y ni siquiera hiciera gesto de dolor alguno.

\footnotetext{
${ }^{25}$ FOUCAULT, Michel. As palavras e as coisas, op. cit., p. 66.

${ }^{26}$ AGAMBEN, Giorgio. Bataille e o paradoxo da soberania. Trad. Nilcéia Valdati. Outra Travessia, Florianópolis, n. 5, p. 92, 2005.

${ }^{27}$ SCHMITT, Carl apud AGAMBEN, Giorgio. Bataille e o paradoxo da soberania, op. cit., p. 92.

${ }^{28}$ BATAILLE, Georges. La experiência interior, op. cit., p. 20-21.

${ }^{29}$ NIETZSCHE, Friedrich. Fragmentos póstumos. v. II (1875-1882). Trad. Manuel Barrios \& Jaime Aspiunza. Madrid: Tecnos, 2008, p. 129.

${ }^{30}$ ibidem, p. 356.
} 
Toda seriedad y toda pasión y todo lo que importa de verdad a los seres humanos es quijotismo, es bueno saberlo para algunos casos; normalmente es, por el contrario mejor no saberlo. ${ }^{31}$

Segundo o filósofo dionisíaco, como se vê, o livro de Cervantes é ao mesmo tempo um dos mais nocivos e o que mais causa riso. De leitura áspera, faz com que todas as preocupações pessoais percam sua importância, pois nos dá a entender que tudo, ao final, é quixotismo. De sorte que, acaso, Nietzsche tenha se deparado pela primeira vez com a noção da "morte de Deus" por meio da leitura do livro de Cervantes, o qual em 15 de agosto de 1859 pedia à sua mãe como presente para o seu décimo quinto aniversário. Desde a escola de Pforta, em carta, teria escrito: “En primer lugar deseo el Don Quijote, traducido por Tiek, 25 groschen de plata" ${ }^{32}$.

A nosso ver, nas aventuras da narrativa quixotesca o que está em questão é a estabilidade do ser das coisas no mundo; como diz Quixote: “y así, eso que a ti te parece bacia de barbero me parece a mi el yelmo de Mambrino, y a otro le parecerá otra cosa" ${ }^{33}$. No quinto livro de La ciencia jovial, no aforismo seguinte ao que Nietzsche tece suas considerações acerca das consequências do fato de que "Dios ha muerto", pode se ler:

la vida se há erigido sobre la apariencia, quiero decir, el error, el engaño, la simulación, la ofuscación, el autoenmascaramiento, y [...] la forma más grande de la vida siempre se ha mostrado siempre de lado de los politropoi [formas multiformes] más carentes de escrúpulos. ${ }^{34}$

Com a percepção de que tudo, ao final, pode se apresentar como quixotismo vislumbra-se a ideia de que a "vontade de verdade" poderia não ser mais que "una oculta voluntad de muerte"35. Assim, longe das interpretações humanistas, Nietzsche pode ter vislumbrado no Quixote não o exemplo do cavaleiro idealista e sim a percepção de que o "trono está vazio". Pôde-se, assim, suspender uma fé: "una fe de milenios, la fe de Cristo, también la fe de

\footnotetext{
${ }^{31}$ NIETZSCHE, Friedrich. Correspondencia. v. III (Enero 1875 - Diciembre 1879). Trad. Andrés Rubio. Madrid: Trotta, 2009, p. 126.

32 idem, Correspondencia. v. I (Junio 1850 - Abril 1869). Trad. Luis Enrique de S. Guervós. Madrid: Trotta, 2005, p. 104.

${ }^{33}$ SAAVEDRA, Miguel de Cervantes. El ingenioso hidalgo Don Quijote..., op. cit., p. 327.

${ }^{34}$ NIETZSCHE, Friedrich. La ciencia jovial. In: Friedrich Nietzsche I. Trad. Germán C. Cuenca. Madrid: Gredos, 2009, p. 784.

${ }^{35}$ ibidem, p. 784.
} 
Platón, de que Dios es la verdad, de que la verdad es divina" ${ }^{36}$.

A metalinguagem é o que nos tira o sossego. Por meio dela nos damos conta do infinito da linguagem, a qual fica em suspenso, sem corresponder com exatidão e plenitude a algo que viesse a preenchê-la. Borges, em ensaio publicado em Otras inquisiciones, indagou: “¿Por qué nos inquieta que Don Quijote sea lector del Quijote y Hamlet, espectador de Hamlet?". E deu com a resposta de que "tales inversiones sugieren que si los caracteres de una ficción pueden ser lectores o espectadores, nosotros, sus lectores o espectadores, podemos ser ficticios" ${ }^{37}$. De maneira que se nós podemos ser obras de ficção é porque todo o resto já o é. Portanto, não é somente o caso de se tomar consciência de que somos fruto de artifícios, mas de que tudo o é. Essa é a "morte de Deus" da qual nos fala Nietzsche, se entendemos de que do que se trata é da percepção da ausência de fundamento. A inquietação, desse modo, parece ser aquela que Bataille confessou no prefácio de sua Experiencia interior:

¿qué es de nosotros cuando, desintoxicados, nos enteramos de lo que somos?, perdidos entre charlatanes, en una noche en la que no podemos sino odiar la apariencia de luz que proviene de los parloteos. ${ }^{38}$

Uma leitura do Quixote como a de Erich Auerbach, em Mimesis, deixa-nos inconformados. A ideia obsessiva de que na narrativa quixotesca "não há nada afora uma divertida confusão" onde se encontra "muito pouco de problemático ou de trágico" ${ }^{39}$, só se justifica na medida em que percebemos na proposta metodológica do autor a velha cisão que separa as esferas da imaginação e da realidade. Auerbach faz da crítica uma ciência e sente pudores de uma interpretação que violente o texto; quer resguardar a verdade e como o historiador busca "determinar o lugar de uma obra dentro de um processo histórico"; não perde de vista aquela obsessão em "esclarecer o que significou a obra para o seu autor e para os seus contemporâneos" ${ }^{40}$.

\footnotetext{
${ }^{36}$ ibidem, p. 785.

${ }^{37}$ BORGES, Jorge Luis. Magias parciales del Quijote. In: Obras completas. 1923 - 1972. Buenos Aires: Emece, 1974, 669.

38 BATAILLE, Georges. La experiencia interior, op. cit., p. 10.

39 AUERBACH, Erich. A Dulcinéia encantada. In: Mimesis. A representação da realidade na literatura ocidental. Trad. Suzi F. Sperber. São Paulo: Perspectiva, 1971, p. 303.

40 ibidem, p. 309.
} 
Mais instigante são as reflexões de Leo Spitzer no ensaio sobre o Perspectivismo lingüístico en el Quijote publicado em 1948 - contemporâneo ao texto de Auerbach, que aparece na edição mexicana de Mimesis de 1950. O foco na questão da polionomasia traz a tona uma postulação sobre a instabilidade dos significantes da linguagem de crucial importância para toda uma tradição crítica pós autonomista.

Enquanto Auerbach enfatiza, uma vez mais, que "Deve haver poucos amantes da arte literária que não liguem a Dom Quixote a concepção da grandeza idealista" ${ }^{41}$, Spitzer traz à luz a ideia de que "Cualquier lector del Quijote queda sorprendido por la inestabilidad de los nombres de los principales personajes de la novela" ${ }^{42}$. Destacando a "superabundancia de nombres, de palabras y de lenguas, la polionomasia, la polietimología y el poliglotismo" da narrativa, pôde, o crítico austríaco, reconhecer o "perspectivismo lingüístico del artista Cervantes", enfatizando que "la transparencia del lenguaje es una realidad solamente para Dios" ${ }^{43}$.

De sorte que Spitzer coloca em suspenso a crença da inequivocidade das palavras. Essa possibilidade, se existe, é reservada a um plano que não corresponde mais ao das relações que passam a se efetivar com a modernidade. Lembremos, mais uma vez, a reflexão de Foucault - que, como destacou recentemente Raúl Antelo, teria sido o responsável por traduzir ao francês a conferência de Spitzer que abre o livro onde se encontra o ensaio sobre o Quijote $^{44}$ - em As palavras e as coisas:

Dom Quixote desenha o negativo do mundo do Renascimento; a escrita cessou de ser a prosa do mundo; as semelhanças e os signos romperam sua antiga aliança; as similitudes decepcionam, conduzem à visão e ao delírio; as coisas permanecem obstinadamente na sua identidade irônica: não são mais do que o que são; as palavras erram ao acaso, sem conteúdo, sem semelhança para preenchêlas; não marcam mais as coisas; dormem entre as folhas dos livros, no meio da poeira. A magia, que permitia a decifração do mundo descobrindo as semelhanças secreta sob os signos, não serve mais senão para explicar de modo delirante por que as analogias são sempre frustradas. ${ }^{45}$

\footnotetext{
${ }^{41}$ ibidem, p. 300.

${ }^{42}$ SPITZER, Leo. Perspectivismo lingüístico en el Quijote. In: Lingüística e historia literaria. Trad. José Perez Riesgo. Madrid: Editorial Gredos, 1955, p. 137.

${ }^{43}$ ibidem, p. 172.

${ }^{44}$ ANTELO, Raúl. O sabor do perspectivismo. Revista Landa, Florianópolis, v. 1, n. 2, p. 230, 2013.

${ }^{45}$ FOUCAULT, Michel. As palavras e as coisas, op. cit., p. 65.
} 
O quixotismo, por meio da instabilidade do significante, expressa a condição trágica de nossa contemporaneidade, a qual não deve ser ignorada se quisermos, alguma vez, desestabilizar a "república cristã" que através do humanismo insiste em desterrar, como "gente inútil", os "disparatados".

Em carta a Gershom Scholem datada de 11 de agosto de 1934, Walter Benjamin exaltava "o sentido da 'inversão" kafkiana que buscaria "transformar a vida em escrita", e se remete ao texto de Cervantes com as seguintes palavras: "O Dasein de Sancho Pança é exemplar porque, na verdade, consiste em sua própria leitura, ainda que insensata e quixotesca" ${ }^{46}$. A sugestão parece ser a de não fingimento com relação à condição de orfandade que nos acomete. Somente a partir de então se poderia abandonar a índole servil de um pensamento que retorna sempre às verdades obtusas. Dessa maneira, a instabilidade do significante manifestada na narrativa cervantina e a tragicidade dela decorrente poderiam vir a ser mananciais de potência, se compreendidas dentro do contexto daquilo que Bataille chamou de "método de meditação". Vejamos:

El momento en que la poesía renuncia al tema y al sentido es, desde el punto de vista de la meditación, la ruptura que le opone a los balbuceos humillados de la ascética. Pero cuando llega a ser un juego sin regla, y en la imposibilidad, por su carencia de tema, de determinar efectos violentos, el ejercicio de la poesía moderna se subordina, a su vez, a la posibilidad. ${ }^{47}$

Quer dizer, só existirá possibilidade na medida em que desestabilizarmos o sentido; continuar pensando que a literatura é representação ou "imitação" da realidade, como entendia Auerbach, retira-nos toda possibilidade de um agir ético, pois que a tarefa do crítico não seria mais do que a de buscar aquele significado preanunciado dentro de um plano, ou de uma estrutura figural; a atividade se reduz, como se perceberá, a um mero cumprimento de tarefas demandadas.

\footnotetext{
${ }^{46}$ No original: "Sancho Pansas Dasein ist musterhaft, weil es eigentlich im Nachlesen des eignen wenn auch närrischen und donquichotesken besteht". Cf. BENJAMIN, Walter \& SCHOLEM, Gershom. Briefwechsel. 1933-1940. Frankfurt: Suhrkamp, 1997, p. 167. Com o auxílio da colega Eliane Stein, traduzimos a sentença de forma distinta da apresentada por Neusa Soliz na edição brasileira, que diz: "O Dasein ('estar-aí') de Sancho Pança é exemplar, porque na verdade consiste na releitura da própria, com o que ela tem de louca e quixotesca". Cf. BENJAMIN, Walter e SCHOLEM, Gershom. Correspondência. 1933-1940. Trad. Neusa Soliz. São Paulo: Perspectiva, 1993, p. 188.

${ }^{47}$ BATAILLE, Georges. La experiência interior, op. cit., p. 198.
} 
No capítulo dez da segunda parte do Quixote, capítulo que serve de base para as conclusões de Auerbach sobre o livro, o narrador conta ao leitor que o autor "desta grande historia a contar lo que en este capítulo cuenta, dice que quisiera pasarle en silencio, temeroso de que no había de ser creído" ${ }^{48}$. Devemos ter em mente, claro, que o suposto autor do livro é o historiador árabe Cide Hamete Benengeli, e o narrador, apenas seu tradutor. Pois bem, o então Hamete Benengeli teria hesitado em escrever esta passagem da história das aventuras de Quixote, pois pensava que não Ihe fossem crer. Ainda assim, o narrador (tradutor) escreve "aunque con este miedo y recelo, las escribió de la misma manera que él [Quixote] las hizo, sin añadir ni quitar a la historia un átomo de la verdad" ${ }^{49}$. Então vemos que o narrador, aprovando a decisão do autor, exalta: "y tuvo razón, porque la verdad adelgaza y no quiebra, y siempre anda sobre la mentira, como el aceite sobre el agua" ${ }^{50}$.

Segundo o Dicionário de sentenças latinas e gregas, de Renzo Tosi, o provérbio teria derivado da expressão latina "Veritatem laborare nimis saepe... exstingui numquam" ${ }^{51}$. Mas veja que essa passagem introdutória ao capítulo, ao procurar alabar os "discursos de verdade" demonstra, ao mesmo tempo, os procedimentos de inventividade de toda tradução e, por conseguinte, de toda escritura. O leitor atento não pode deixar de sentir a fina ironia que a situação apresenta. Se o autor escreveu a história da mesma maneira que a personagem a viveu, temos que o texto deve ser de todo disparatado tal qual o acontecimento; mesmo "sin añadir ni quitar un átomo de la verdad" do que se trata é de desvarios, quixotismos. Por outro lado, o provérbio, que quer ser uma pretensa defesa da honestidade, acaba por ratificar a flexibilidade dos "discursos da verdade": "la verdad adelgaza"; e se, ela, "siempre anda sobre la mentira" pode ser que esteja sempre fundada sobre o infundado.

\footnotetext{
${ }^{48}$ SAAVEDRA. Miguel de Cervantes. El ingenioso hidalgo Don Quijote..., op. cit., p. 835.

${ }^{49}$ ibidem, p. 835.

${ }^{50}$ ibidem, p. 835.

51 "A verdade com grande frequência sofre, mas nunca se extingui". Cf. TOSI, Renzo. Dicionário de sentenças latinas e gregas. Trad. Ivone C. Benedetti. São Paulo: Martins Fontes, 1996, p. 138.
} 